\title{
O “DISCURSO DE OUTREM" EM BAKHTIN E O CÍRCULO: POR UMA COMPREENSÃO RESPONSIVA DO TEXTO' ${ }^{1}$
}

\author{
THE "SPEECH OF OTHERS" IN BAKHTIN AND THE CIRCLE: FOR A \\ RESPONSIBLE UNDERSTANDING OF THE TEXT
}

\author{
Telma Cristina Gomes Da Silva \\ Universidade Federal da Paraíba, João Pessoa, Paraíba, Brasil \\ telmapedist@hotmail.com
}

Resumo: Este artigo apresenta as contribuições de os estudos bakhtinianos para a compreensão responsiva do enunciado/texto. Examinamos as marcas linguístico-discursivas responsáveis pela presença do discurso de outrem em comentários discentes produzidos em e-fóruns acadêmicos em um curso na modalidade de ensino a distância. Consideramos esse discurso como o responsável pelas formas de transmissão e recepção de sentidos produzidos no/para a construção do enunciado/texto dos alunos em e-fóruns. Analisamos quatro comentários discentes produzidos, como respostas a temáticas nos e-fóruns em um componente curricular direcionado para o ensino de língua portuguesa.

Palavras-chave: Bakhtin; Dialogismo; Compreensão Responsiva

Abstract: This article presents the contributions of Bakhtinian studies to the responsive understanding of the utterance/text. We examined the linguistic-discursive marks responsible for the presence of the speech of others in student comments produced in academic e-forums in a course in the distance learning modality. We consider this discourse to be responsible for the forms of transmission and reception of meanings produced in / for the construction of the utterance/text of students in e-forums. We analyzed four student comments produced, as responses to topics in the e-forums, in a curricular component aimed at teaching Portuguese language.

Keywords: Bakhtin; Dialogism; Responsive Comprehension

\footnotetext{
${ }^{1}$ Este trabalho é resultante de uma tese doutorado defendida, na área de Linguística e Práticas Sociais, sobre a compreensão responsiva discente em e-fóruns acadêmicos.
} 


\section{INTRODUÇÃO}

A discussão desenvolvida neste artigo está pautada em manuscritos de Bakhtin/Volochínov (2010) e Bakhtin (1993) nos quais encontramos a concepção de discurso de outrem assinalando suas implicações para a construção de sentidos do/para o enunciado/texto.

Ao longo deste texto explicitamos a importância dessa noção para o estudo do enunciado/texto, mostrando-a como a responsável pelas formas de transmissão e recepção enunciativas. Para exemplificar analisamos quatro comentários de alunos produzidos em efóruns voltados para o ensino de língua portuguesa no ensino a distância. Analisando os movimentos discursivos realizados por alunos para a construção de sentidos de seus enunciados/textos.

Este artigo está organizado em quatro partes, incluindo a introdução na qual apresentamos brevemente o trabalho. $\mathrm{Na}$ seção 1, O discurso de outrem e o sentido do enunciado/texto, expomos a concepção de dialogismo como constitutivo da linguagem conforme os pressupostos bakhtinianos. Na subseção 1.1, As manifestações do discurso de outrem, trazemos as formas de manifestação do discurso de outrem apresentando as noções de discurso demarcado e discurso não demarcado. Na subseção 1.2, $\mathrm{O}$ acento apreciativo em Bakhtin e o Círculo, tratamos do papel do acento apreciativo para a (re)atualização de sentidos no/do enunciado/texto. Na seção 2, A construção de sentidos do enunciado/texto pela interação com o discurso de outrem, analisamos quatro comentários discentes; e, finalmente, tecemos considerações acerca do trabalho.

\section{0 “DISCURSO DE OUTREM” E O SENTIDO DO ENUNCIADO/TEXTO}

Bakhtin/Volochínov (2010) entendem a linguagem como derivada do processo de comunicação verbal. Nessa ótica, todo enunciado independentemente de sua extensão é compreendido como um ato dialógico de sujeitos situados que produzem discursos a partir do discurso de outrem. Por este ângulo, Fiorin (2006) defende que todo o discurso é atravessado pelo discurso do "outro" assim sendo os discursos são construídos entre as relações de sentidos constituídas por diferentes perspectivas acerca de um mesmo objeto de discurso.

Entender o princípio do dialogismo, como constitutivo da linguagem, requer considerar que todo e qualquer ato enunciativo precede e antecede o enunciado de sujeitos situados. Porque os objetos de discurso são constituídos na/pela interação de ideias entre dois ou mais sujeitos sociais. Assim a compreensão de um enunciado/texto implicará entender que há uma inter-relação entre diferentes pontos de vistas na/para a construção de sentido do enunciado/texto.

Contudo as questões de sintaxe constituem o maior problema no que concerne à compreensão da língua em uso e a sua evolução, segundo apontado pelos estudos bakhtinianos. Porque às formas sintáticas aproximarem-se das formas concretas de enunciação em razão disso a sintaxe de uma língua não deve ser estuda sem considerar o contexto enunciativo.

De acordo com a perspectiva bakhtiniana, "todas as análises sintáticas do discurso constituem análises do corpo vivo da enunciação, portanto, é ainda mais difícil trazê-las a um sistema abstrato da língua" (BAKHTIN/VOLOCHÍNOV, 2010, p. 146). Em outros termos, as formas sintáticas são como a língua em uso sempre em movimento, em evolução e, portanto, somente é possível analisá-las a partir de uma teoria da enunciação não restrita às categorias gramaticais. 
Porque as categorias gramaticais delimitam o estudo da língua para o sistema abstrato, separando-o da enunciação concreta. Logo os enunciados não podem ser compreendidos em sua essência, quando estão descontextualizados. Do mesmo modo, acontece com os parágrafos recortados de um texto que permitem composições variadas, com uma só palavra, ou ainda, uma sequência de orações que impedem a apreensão do enunciado como um todo significativo. Por isso, nenhum parágrafo deve ser entendido como uma ideia completa já que estar isolado das definições ideológicas existentes no ato enunciativo (BAKHTIN/VOLOCHÍNOV, 2010).

Nesta concepção, o estudo de um parágrafo isolado altera o sentido do texto e, portanto, não interessa aos bakhtinianos que se preocupam em compreender as formas de interação verbal e enunciações completas por essas trazerem as marcas ideológicas do discurso (entonações), favorecendo a apreensão de sentidos construídos no/pelo enunciado/texto.

Por isso, estudar o fenômeno discursivo conhecido como discurso de outrem ${ }^{2}$ discurso direto, discurso indireto, discurso indireto livre - torna-se produtivo para compreender a orientação sociológica e, também, como a voz do "outro" é integrada a outros discursos no processo de construção de sentidos de enunciados/textos.

Essa inter-relação entre discursos não acontece aleatoriamente, mas sim em uma cadeia comunicativa na qual todo enunciado enseja uma resposta que ainda será construída, ou seja, uma compreensão responsiva ativa de seu interlocutor. Nessa óptica, "o interlocutor é sempre uma resposta, um enunciado e, por isso, todo dialogismo são relações entre enunciados" (FIORIN, 2006, p. 32). Então a réplica do "outro" é presumida e/ou esperada pelo "eu" sendo constitutiva do discurso deste sujeito.

\subsection{AS MANIFESTAÇÕES DO “DISCURSO DE OUTREM"}

Fiorin (2006) afirma, ancorado no pensamento bakhtiniano, que o dialogismo manifesta-se de duas formas: não marcada no discurso e marcada pelo discurso de outrem. No entanto, o linguista esclarece que o dialogismo não deve ser entendido apenas como uma composição introduzida pelo enunciador em seu discurso, mas sim como um diálogo amplo entre diferentes vozes sociais que atualizam e constroem novos sentidos para o enunciado/texto.

De acordo com esse estudioso, o discurso demarcado - discurso direto, discurso indireto, o uso de aspas e o uso da negação - é explicitamente citado e separado do discurso citante que o incorporou sendo um discurso objetivado. Por outro lado, o discurso não demarcado (indireto livre) é internamente dialogizado tendo uma separação interna entre o enunciado citado e o enunciado citante (FIORIN, 2006).

Bakhtin/Volochínov (2010, p. 150, grifos dos autores) caracterizam o discurso citado como "o discurso no discurso, a enunciação na enunciação, mas é, ao mesmo tempo, um discurso sobre o discurso, uma enunciação sobre a enunciação". Para eles o discurso citado não constitui um tema inserido no interior de outro discurso, mas sim um discurso integral inserido em outro discurso que mantém sua autonomia estrutural e semântica sem modificar o enredo do discurso citante ${ }^{3}$.

Ao mesmo tempo o discurso citado é parte estrutural de outro discurso integrante da enunciação citada compondo sua unicidade temática e acrescentando sua própria temática, ou seja, tornando-se o tema de um tema. Essa autonomia do discurso citado é entendida pelo sujeito

\footnotetext{
${ }^{2} \mathrm{O}$ discurso de outrem recebe diferentes denominações dentro dos trabalhos desenvolvidos pelos estudiosos do Círculo bakhtiniano e também entre os pesquisadores que trabalham com a teoria bakhtiniana, como, por exemplo, "discurso alheio", "discurso reportado", "discurso citado", etc.; assim sendo, adotamos as denominações segundo o autor citado ou como forma de referenciação no texto.

${ }^{3}$ Nomenclatura empregada por Faraco (2009).
} 
como a enunciação de outro sujeito do discurso, quer dizer um ponto de vista independente originado de outro contexto enunciativo introduzido pelo enunciador para ser ampliado, elogiado, rechaçado, etc. Portanto, o discurso citado mantém-se estável em relação a seu conteúdo e em sua estrutura enunciativa estabelecendo um elo entre enunciações distintas no que diz respeito à construção da língua (BAKHTIN/VOLOCHÍNOV, 2010).

Bakhtin/Volochínov (2010) asseguram que essa ligação entre diferentes discursos consiste em uma reação ativa da palavra a palavra, e, por isso, se distingue do diálogo cotidiano no qual os discursos são separados em um mesmo contexto. Ao contrário, o discurso citado é um discurso direto incorporado ao discurso citante com a integração entre duas vozes em um único ato enunciativo.

Ao abordar sobre a circulação do discurso na mídia, Cunha (2009) investiga as escolhas lexicais, a retomada do discurso de outro e a reacentuação desse discurso pelo enunciador em charges e cartas dos leitores. Segundo ela, esses gêneros discursivos são constituídos por meio da "memória discursiva", "posicionamento do autor" e "sentido atribuído à palavra alheia". Esses aspectos constituem semelhantemente o gênero e-fórum de discussão porque os comentários produzidos nesse trazem conhecimentos prévios dos sujeitos, seus pontos de vista e sua compreensão do tema em discussão.

A referida linguista acrescenta que as escolhas lexicais estão associadas aos processos de produção de sentido e às atividades sistêmicas da língua. Essas escolhas possuem um caráter axiológico associado à compreensão de relações dialógicas constituídas no tempo-espaço pelo enunciador. Contudo, segundo essa estudiosa, o enunciador não é a única fonte de criação do enunciado/texto, tão pouco dos sentidos atribuídos a ele tendo em vista que todo enunciado é originado em uma cadeia discursiva mais ampla em que diferentes perspectivas interagem em torno de uma mesma temática. Essa temática resulta de um processo de interação entre diferentes vozes que atualizam sentidos da/para a palavra, (re)acentuando o já-dito em outro momento enunciativo (CUNHA, 2009). Essa (re)acentuação refere-se ao acento apreciativo, isto é, aos juízos de valor responsáveis pela circulação da palavra e por sua atualização em outros contextos.

\subsection{O ACENTO APRECIATIVO EM BAKHTIN E O CÍRCULO}

Em Marxismo e filosofia da linguagem: problemas fundamentais do método sociológico na ciência da linguagem, Bakhtin/Volochínov (2010) versam a respeito da importância do acento apreciativo para a atualização dos sentidos do/no enunciado/texto. Segundo eles,

\footnotetext{
a mudança do acento avaliativo da palavra em função do contexto é totalmente ignorada pela linguística e não encontra nenhuma repercussão na sua doutrina da unicidade da significação. Embora os acentos sejam privados de substancia, é a pluriacentuação que dá vida à palavra. O problema da pluriacentuação deve ser estreitamento relacionado com o da polissemia. Só assim é que ambos os problemas poderão ser resolvidos (BAKHTIN/VOLOCHÍNOV, 2010, p. 111).
}

Essa inscrição da palavra em outras enunciações e/ou contextos a atribui novos sentidos em razão da transposição da palavra para outra situação comunicativa. Essa transposição a confere uma nova carga semântica, uma nova conotação e, portanto, novo sentido axiológico.

Cunha (2009) ressalta que a concepção bakhtiniana de acento apreciativo apresenta os seguintes aspectos: 1) tom apreciativo; 2) julgamento de valor; 3) caráter axiológico; 4) ponto de vista do autor; 5) e efeito de deslocamento temático inerente à circulação discursiva. Esses 
aspectos estão associados às relações dialógicas e à construção do sentido do enunciado/texto pelo interlocutor. Porque como a palavra é viva, ela transforma-se e recebe diferentes valorações conforme seu contexto enunciativo.

No que concerne a essa questão, Bakhtin/Volochínov (2010, p. 109-110) afirmam que

o sentido da palavra é totalmente determinado por seu contexto. De fato, há tantas significações possíveis quantos contextos possíveis. No entanto, nem por isso a palavra deixa de ser uma. Ela não se desagrega em tantas palavras quantos forem os contextos nos quais ela pode se inserir. Evidentemente, essa unicidade da palavra não é somente assegurada pela unicidade de sua composição fonética, há também uma unicidade inerente a todas as suas significações.

Com isso a palavra mantém o significante e o significado, porém esse último pode mudar segundo a situação comunicacional. Todavia a "palavra" não assumirá uma significação diferente a cada enunciação, até porque, isso tornaria inviável a utilização efetiva da língua. Nessa ótica, segundo Bakhtin, o acento apreciativo dá existência a uma "nova" palavra carregando-a de novo(s) significado(s), porque

[...] a palavra viva, a palavra completa, não conhece um objeto como algo totalmente dado; o simples fato de que eu comecei a falar sobre ele [objeto] já significa que eu assumi uma certa atitude sobre - não uma atitude indiferente mas uma atitude efetiva e interessada. E é por isso que a palavra não designa apenas um objeto, como uma entidade pronta, mas também expressa, por sua entoação (uma palavra realmente pronunciada não pode deixar de entoada, porque a entoação existe pelo simples fato de ser pronunciada) minha atitude valorativa em relação ao objeto, sobre o que é desejável ou indesejável nele, torna-se um momento constituinte do evento vivo em processo (BAKHTIN, 1993, p. 50).

Essa ideia é a base dos estudos bakhtinianos já que toda palavra possui um valor ideológico conferido por sua atualização no discurso de outrem. Nessa visão, a palavra alheia adquire sentido(s) à medida que é citada em outros contextos. Assim o discurso de outrem antes estudado pela perspectiva sintática da língua passa a ser observado pelas relações dialógicas representadas por discursos concretos a exemplo do discurso citado e discurso citante, bem como pelas formas marcadas e não marcadas do discurso, entre outros (CUNHA, 2009).

\section{A CONSTRUÇÃO DE SENTIDOS DO ENUNCIADO/TEXTO PELA INTERAÇÃO COM O "DISCURSO DE OUTREM"}

Analisamos nesta seção as marcas linguístico-discursivas responsáveis pela presença do discurso de outrem em enunciados discentes produzidos em dois e-fóruns direcionados para o ensino de língua portuguesa. Ilustremos com a análise de comentários recortados do e-fórum 01 no qual se discutiu o texto Falando em leitura de Maria Helena Martins para motivar a discussão sobre a concepção de leitura do sujeito-leitor - primeiro conteúdo temático da disciplina PI - e conhecer o perfil de aluno leitor ingresso no curso investigado. Na sequência analisamos os comentários:

[...] Gosto de ler jornal, revistas e artigos referentes a educação. Concordo com o texto lido da (trilha) ao afirmar que "Falar das próprias vivência nos faz aptos para melhor pensar e solucionar problemas", as leituras que eu faço do meu dia- a- dia, me faz repensar e tentar ver a vida de uma forma diferente, pois a medida que lemos 


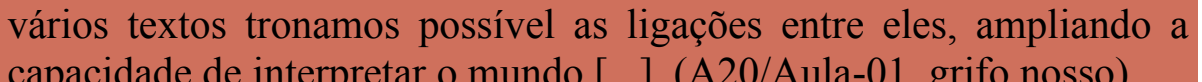
capacidade de interpretar o mundo [...]. (A20/Aula-01, grifo nosso).

Fonte: dados do corpora pesquisado.

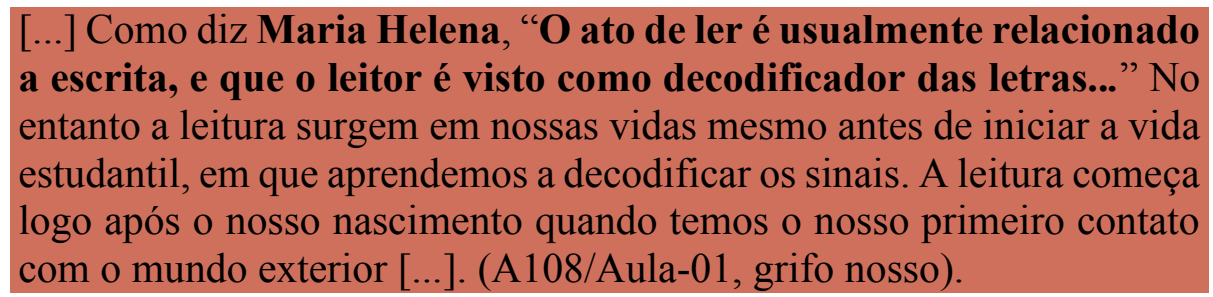

Fonte: dados do corpora pesquisado.

Observamos que esses enunciados discentes trazem concepções de leitura diferentes como apresentam os excertos: "Gosto de ler jornal, revistas e artigos referentes a educação" enunciado por $\mathrm{A} 20^{4}$ e "A leitura começa logo após o nosso nascimento quando temos o nosso primeiro contato com o mundo exterior" enunciado por A108. No primeiro, A20 associa a noção de leitura à escrita de natureza intelectual e acadêmico-científica. No segundo, A108 relaciona o ato de ler as experiências vivenciadas com o mundo. Essas concepções de leitura resultam das relações dialógicas estabelecidas pelos alunos com seus conhecimentos prévios, participantes da interação e o texto "Falando em leitura" no e-fórum 01. Por meio dessas interações, os enunciadores/alunos constroem seus pontos de vistas sobre o objeto discutido.

Ademais esses enunciadores/alunos circunscrevem seus discursos pela marca linguístico-discursiva de primeira pessoa já que empregam o discurso direto no presente do indicativo demarcando a presença do discurso de outrem com aspas. Assim os enunciadores retomam o texto motivador da discussão no e-fórum 01 .

A utilização das aspas propicia que os enunciadores mantenham um distanciamento em relação ao discurso alheio e construam seus enunciados/textos pela inserção do discurso de outrem em seus enunciados. Estabelecendo um diálogo com o discurso do outro - professor e/ou texto motivador - como uma estratégia discursiva do leitor responsivo ativo ${ }^{5}$.

Essa integração, entre os discursos citado e citante, viabiliza um diálogo em sentido amplo, criando condições para a construção do enunciado/texto na situação comunicacional. Nessa ótica, conforme Bakhtin (2010), as relações dialógicas - alternâncias entre os sujeitos do discurso - permitem a observação do confronto entre diferentes refrações - vozes e/ou posições sociais - sobre uma temática.

Esse processo de apropriação e constituição de discursos, de acordo com Cunha (2009), põe em evidência a importância da memória discursiva para a transmissão e recepção de discursos e, portanto, construção de sentidos de/para os enunciados/textos. Essa linguista acrescenta que a memória discursiva influencia as escolhas lexicais, as construções e as retomadas não explícitas de segmentos pelo enunciador no processo de construção e compreensão do enunciado/texto.

Nessa dimensão, a construção de sentidos de um enunciado/texto passa pelas relações dialógicas que mobilizam a palavra em diferentes contextos. Essa mobilidade é responsável pelos sentidos atribuídos aos enunciados, transportando a interdiscursividade, preservando significados e deslocando-os no espaço-tempo pelas relações dialógicas estabelecidas entre os sujeitos do discurso nas esferas sociais.

\footnotetext{
${ }^{4}$ Nessa abreviação o "A” significa aluno e o número sua posição no momento da interação no e-fórum/aula.

${ }^{5}$ É aquele sujeito responsável pelo seu dizer, ou seja, quem constrói seu ponto de vista a partir da interação social.
} 
Nas obras Para uma filosofia do ato (1993) e Estética da Criação Verbal (2011), Bakhtin discorre sobre a arquitetônica da alteridade esclarecendo o papel das interações sociais constituídas pelo enunciador na/para construção do enunciado/texto. Essa arquitetônica é ancorada em um tripé - o "eu-para-mim", o "eu-para-outro" e "outro-para-mim" - que se refere à unicidade do "eu" e a sua restrição quanto à constituição e a compreensão do enunciado/texto. Partindo dessa concepção, o estudioso põe em evidencia a interação verbal para a completude do sentido do enunciado/texto reforçando a importância do olhar estrangeiro para a constituição do sujeito, discurso e mundo. Porque o "eu" não se constitui apenas mediante suas experiências pessoais, mas também pela compreensão que o "outro" possui dele.

Os comentários discentes produzidos, nos e-fóruns acadêmicos, são constituídos no processo de interação entre "professor-aluno", "aluno-texto", "aluno-aluno" e "aluno-elemesmo". Essas relações dialógicas revelam a arquitetônica da alteridade, tornando a apreciação do "outro" fundamental para a constituição do comentário discente e, portanto, construção dos sentidos presentes nos enunciados/textos. Por essas relações, alunos e professor(es) tecem seus comentários em uma grande rede social pela qual enunciados/textos são produzidos em conformidade com as experiências individuais e sociais dos participantes da interação.

Ponzio (2011) ressalta, fundamentado nos estudos bakhtinianos, que a interpretação de uma obra - enunciado -, geralmente, é embasada nas condições de produção da época mais próxima. Porém o fechamento dessa obra em uma época restringe sua compreensão, pois os enunciados são criados para além de suas fronteiras, não se limitando a um momento específico. O conhecimento das relações dialógicas constituídas para a criação de um enunciado/texto torna-se, então, indispensável para atribuir sentidos ao enunciado/texto.

Esse estudioso acrescenta que a capacidade de transportar sentidos de um enunciado a outro os adaptando a novos contextos e situações de comunicação caracteriza a palavra por sua "plurivocalidade" e "indeterminação semântica". Ele complementa que o enunciado/texto reflete pela entonação as relações afetivas do enunciador com o tema abordado. $\mathrm{O}$ ato enunciativo representa, então, uma dupla orientação da linguagem pelo sujeito expor seu ponto de vista acerca de algo ou para alguém.

Essa questão da orientação para o "outro" nos remete para os estudos bakhtinianos sobre os discursos indireto, direto e suas variantes. Nesses estudos, Bakhtin/Volochínov (2010, p. 142) enunciam que na língua russa: "As marcas do discurso indireto são fracas, e durante a conversa, podem ser facilmente confundidas com as do discurso direto". Por outro lado, a língua portuguesa distingue os discursos direto e indireto por meio da sintaxe - emprego dos tempos e modos verbais, o uso de conjunções, etc.

A orientação do discurso, segundo os referidos estudiosos, acontece a partir de dois esquemas básicos de transmissão do discurso de outrem: 1) o discurso direto - uma reprodução idêntica da voz de outrem pelo empredo de aspas ou travessão, normalmente, auxiliada por um verbo declarativo - concordar, alegar, afirmar, etc.; 2) e o discurso indireto - uma construção mais complexa que permite um grau maior ou menor de apreciação do enunciador que pode seguir duas direções: i) o posicionamento do enunciador com o conteúdo semântico idêntico ao discurso de outrem transmitindo o sentido objetivo da entonação do sujeito "outro"; e ii) a apreensão do conteúdo semântico e do estilo do discurso de outrem pelo enunciador.

Trabalhar com a concepção bakhtiniana de discurso de outrem exige que apresentemos uma caracterização das construções discursivas - direta e indireta - com os esquemas e suas variantes. De acordo com Bakhtin/Volochínov (2010), os esquemas de transmissão do discurso de outrem se materializam por suas variantes sendo essas formas linguístico-discursivas responsáveis pelas mudanças sucedidas em uma língua natural com o passar do tempo. Essas variantes estão entre as fronteiras da gramática e da estilística propiciando o estudo da língua viva. 
Ao caracterizar os esquemas e suas variantes, esses estudiosos estabelecem que o discurso indireto apresenta três variantes: 1) a variante analisadora do conteúdo (VAC) pela qual o enunciador apreende o tema da enunciação, facilitando inserção de réplicas no discurso narrativo; nesse caso, o "eu" tematiza o discurso do "outro" preservando o conteúdo semântico. Essa variante se desenvolve melhor em um contexto racional e dogmático em que o sujeito elabora seu ponto de vista pela relação com a voz de uma autoridade, como os discursos científicos, filosóficos ou políticos; 2) a variante analisadora da expressão (VAE) possibilita ao enunciador apropriação do conteúdo semântico e do estilo do outro sujeito, sendo perceptíveis as marcas do discurso de outrem pelo uso de aspas. Essa variante permite também que o enunciador expresse sua opinião individual sobre o objeto de discurso, oferecendo-lhe uma maior expressão; 3) e a variante impressionista (VI) que é uma intermediária entre as outras duas variantes por efetivar uma junção entre o conteúdo do discurso de outrem e a expressão do enunciador. Essa é uma forma bastante empregada no discurso literário para a transmissão do discurso interior das personagens.

Esses estudiosos apresentam ainda outras três variantes do discurso direto: 1) o discurso direto preparado $(D D P)$ caracterizado como um tipo de discurso direto originado do indireto que antecipa o conteúdo pelo discurso narrativo e, em seguida, o sujeito acentua com suas próprias palavras o discurso citado; 2) o discurso direto esvaziado (DDE) pelo qual o sujeito transmite, com suas próprias palavras a voz de outrem; nesse caso, o "eu" dar a entonação ao discurso citado do "outro" reduzindo a carga semântica das palavras desse outro e reforçando sua própria voz; 3) e o variante do discurso citado antecipado e disseminado $(V D C A D)$ pelo qual aparece na narrativa um ponto de vista e/ou apreciação da personagem. Ilustremos um caso do discurso direto, com outro enunciado discente recortado do e-fórum 01:

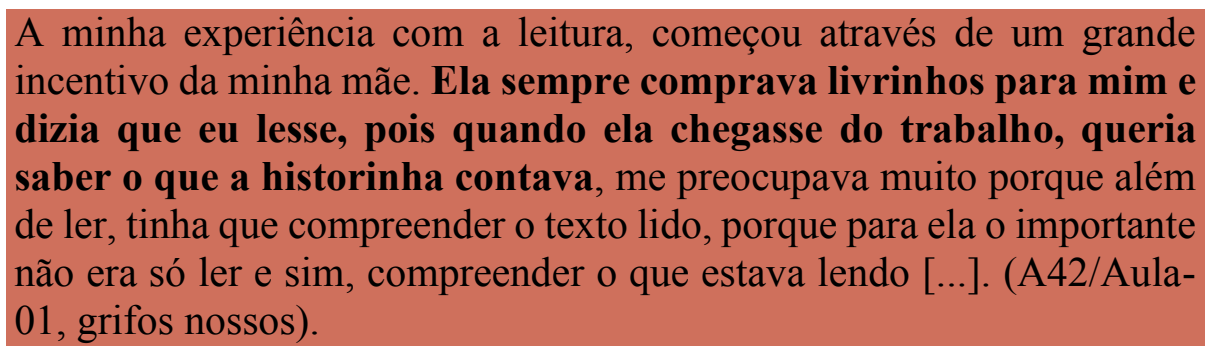

Fonte: dados do corpora pesquisado.

Observamos que o enunciador A42 introduz o tema a partir de sua experiência leitora; em seguida, insere a voz do outro, sendo seu discurso carregado por duas apreciações: 1) a voz do enunciador/aluno que narra sua experiência leitora; 2 ) e a voz de outrem (mãe do aluno) que exigia a compreensão leitora desse enunciador/aluno diariamente sem se satisfazer com a mera decodificação de sinais gráficos, como exemplifica o excerto destacado no enunciado.

Nesse comentário, A42 narra um acontecimento passado por meio da transmissão do discurso da mãe (re)acentuando a segunda voz discursiva. Assim ele constrói seu comentário pelo uso da variante do discurso direto preparado, enfatizando o que lhe interessa no discurso do outro, no caso, que o ato de "ler é compreender e não decodificar".

Verificamos aqui que a memória discursiva auxilia o enunciador a atribuir sentidos para o tema em discussão reportando-se ao discurso de outrem para construir sentidos para seu enunciado/texto. Cunha (2009) destaca que a memória discursiva do enunciador é correlacionada a um já-dito; e, portanto, há uma familiaridade desse sujeito com determinado discurso que lhe permite a apropriação da voz do outro em diferentes situações 
comunicacionais. Essa apropriação do discurso de outrem favorece a construção de sentidos do enunciado/texto.

Ao abordar acerca do discurso não demarcado na obra literária, Bakhtin (2010) afirma que a dialogicidade interna de um discurso não se esgota tematicamente por meio do diálogo direto ou réplicas de diálogo. Porque ela é pré-elaborada na/pela linguagem, como um fenômeno social e, como tal, essa dialogicidade é (re)atualizada historicamente e marcada pelo fenômeno da polissemia. Assim sendo o estudioso defende que "[...] a dialogicidade interna do discurso é o acompanhamento indispensável da estratificação da língua, a consequência de sua superpovoação de intenções plurilíngues" (BAKHTIN, 2010, p. 132). Isto significa que dialogicidade é responsável pela atualização de sentidos dos/para os discursos, e, consequentemente, pela evolução da linguagem humana ${ }^{6}$.

Fiorin (2006) apresenta quatro manifestações do discurso alheio não demarcado: a "polêmica clara", a "polêmica velada", a "paródia e a estilização"7. A polêmica clara consiste em um confronto entre duas ou mais vozes que debatem, abertamente, em defesa de seus pontos de vista, sendo uma delas a orientadora da discussão. Podemos citar como exemplo uma assembleia em que um síndico conduz uma ampla discussão entre diferentes sujeitos sobre determinada pauta.

Exemplificaremos o fenômeno da polêmica clara, com a análise de um comentário recortado do e-fórum 02 "Argumentação" no qual trabalhamos o texto "Diga não as drogas" de Luiz Fernando Veríssimo. Vejamos o enunciado/texto:

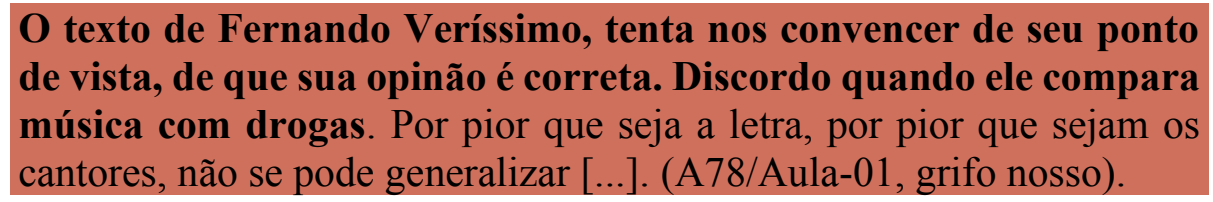

Fonte: dados do corpora pesquisado.

Nesse comentário, A78 dialoga com dois sujeitos para construir seu enunciado/texto, são eles: 1) a professora que gera o tópico de discussão no e-fórum para quem o enunciador/aluno direciona uma resposta, embora, ela não seja citada no discurso; 2) e o texto motivador indicado para leitura, no e-fórum 02 , no qual o autor associa a música brasileira contemporânea a drogas nocivas à sociedade. $\mathrm{O}$ enunciador $\mathrm{A} 78$ discorda do texto motivador por considerar que o autor generaliza ao comparar os estilos de musicais a drogas químicas prejudiciais a saúde. Assim essas duas vozes aliadas aos conhecimentos prévios do enunciado/aluno orientam a construção de sentidos de seu enunciado/texto.

\section{CONSIDERAÇÕES FINAIS}

O estudo assinala que as relações dialógicas estabelecidas pelos enunciadores/alunos, no processo de interação nos e-fóruns, são responsáveis pelos sentidos produzidos em seus comentários. A análise aponta que o enunciador/aluno tem o discurso da professora e do texto motivador, como norteadores da discussão, entretanto, outras vozes sociais - outros alunos, conhecimentos prévios, etc. - ecoam no processo de interlocução influenciando a construção de sentidos para o comentário discente.

\footnotetext{
${ }^{6}$ Não aprofundarmos a discussão sobre a concepção de discurso bivocal para não perder o foco da temática aqui trabalhada. Todavia, sugerimos a leitura da obra Marxismo e Filosofia da Linguagem de Bakhtin/Volochínov (2010) para esclarecimentos acerca dessa forma discursiva.

${ }^{7}$ Por questões de espaço analisamos apenas o primeiro caso de manifestação do discurso demarcado neste artigo.
} 
Essas outras vozes tornam-se as orientadoras dos pontos de vista dos enunciadores/alunos, intervindo diretamente na/para a compreensão do texto, e, também, construção de sentidos do comentário discente. Essa adesão ao discurso do "outro" indica que o principal movimento discursivo dos enunciadores/alunos no e-fórum é a apropriação do discurso de outrem pelo uso da variante (DDE) - discurso direto esvaziado -, pela qual o enunciador se apropria da voz alheia sem referenciá-la em seu discurso. Deste modo o discurso de outrem é o principal responsável pelas formas de transmissão e de recepção de sentidos produzidos no/para a construção do sentido do enunciado/texto dos alunos.

Concluímos que discursos de diferentes contextos enunciativos perpassam os comentários discentes sendo assimilados valores que se refletem na compreensão do texto em discussão. A partir disto, consideramos que os estudos bakhtinianos mostraram-se relevantes para a investigação da compreensão responsiva discente e a construção de sentidos do enunciado/texto por favorecer a identificação e a interpretação de marcas linguísticodiscursivas responsáveis pela presença do discurso de outrem nos comentários analisados.

\section{REFERÊNCIAS}

BAKHTIN, Mikhail. (Volochínov). Marxismo e filosofia da linguagem: problemas fundamentais do método sociológico na ciência da linguagem. Tradução M. Lahud e Y. F. Vieira. 13 ed. São Paulo: HUCITEC, 2010.

BAKHTIN, Mikhail. Para uma filosofia do ato responsável. Tradução de Carlos Alberto Faraco e Cristovão Tezza, 1993. (mimeo).

BAKHTIN, Mikhail. Questões de Literatura e de Estética. Tradução de Aurora F. Bernardini, José Pereira Júnior, Augusto Góes Júnior, Helena Spryndis Nazário e Homero Freitas de Andrade. 6 ed. São Paulo: HUCITEC, 2010.

BAKHTIN, Mikhail. Estética da Criação Verbal. Introdução e tradução de Paulo Bezerra. 6 ed. São Paulo: Martins Fontes, 2011.

CUNHA, Dóris de Arruda C. Circulação, reacentuação e memória no discurso da imprensa. BAKHTINIANA, São Paulo, v. 1, n. 2, 2 sem., 2009, p. 23-39.

FARACO, Carlos Alberto. Linguagem \& Diálogo: as ideias linguísticas do círculo de Bakhtin. São Paulo: Parábola, 2009.

FIORIN, José Luiz. Introdução ao pensamento de Bakhtin. 1 ed. São Paulo: Ática, 2006.

MARTINS, Maria Helena. Falando em Leitura. In: MARTINS, Maria Helena. O que é leitura. São Paulo: Brasiliense. 7 ed, 1986, pg.07-10.

PONZIO, Augusto. A revolução bakhtiniana: o pensamento Bakhtin e a ideologia contemporânea. Organização de tradução Valtemir Mioletto. 1 ed., 2 reimpressão. São Paulo: Contexto, 2011. 
VERÍSSIMO, Luiz F. Diga não as drogas. Disponível em: https://jotapeah.wordpress.com/2009/11/25/diga-nao-as-drogas-luis-fernando-verissimo/ Acesso em 22/04/2020.

Recebido em: 28 de fevereiro de 2019 Aceito em: 20 de dezembro de 2019 Publicado em Maio de 2020 